\title{
Association of ADAM33 gene polymorphisms with asthma in the Uygur population of China
}

\author{
JING WANG $^{1,2}$, JIN WEN $^{3}$, MI-HE-RE-GU-LI SI-MA-YI ${ }^{1}$, YUAN-BING HE $^{1}$, KE-LI-BIE-NA TU-ER-XUN ${ }^{1}$, \\ YU XIA $^{1}$, JIAN-LONG ZHANG ${ }^{1}$ and QI-MAN-GU-LI WU-SHOU-ER ${ }^{1}$ \\ ${ }^{1}$ Department of Respiratory Medicine; ${ }^{2}$ Mobile Postdoctoral Station, The First Affiliated Hospital, \\ Xinjiang Medical University, Urumqi, Xinjiang 830054; ${ }^{3}$ Department of Intensive Care Unit, The Second Affiliated Hospital, \\ Xinjiang Medical University, Urumqi, Xinjiang 830028, P.R. China
}

Received December 18, 2012; Accepted February 22, 2013

DOI: $10.3892 /$ br. 2013.75

\begin{abstract}
Asthma is one of the most common chronic respiratory diseases, affecting $\sim 300$ million children and adults worldwide. Previous studies identified a disintegrin and metalloprotease domain 33 (ADAM33) as an important susceptibility gene for asthma in patients of different nationalities; however, it is unknown whether this relationship exists in ethnically diverse populations. The present study focused on the association between single-nucleotide polymorphisms (SNPs) of the ADAM33 gene and asthma in the Uygur population of China. Three SNPs of ADAM33 (T1, $\mathrm{S}+1$ and $\mathrm{F}+1)$ were genotyped in a case-control study among the Chinese Uygur population, involving 126 adult asthmatic patients and 126 healthy controls. The frequency of the ADAM33 T1 C allele among asthma patients was significantly higher compared to healthy controls (20.6 vs. $11.1 \%$, $\mathrm{P}=0.003)$. The distribution of ADAM33 genotypes differed significantly between the two groups. The frequency of the T1 TC genotype was higher among patients compared to healthy controls [odds ratio $(\mathrm{OR})=2.118, \mathrm{P}=0.016$ ] and the variant genotype, $\mathrm{TC}+\mathrm{CC}$, increased the risk of asthma $(\mathrm{OR}=2.244, \mathrm{P}=0.005)$. Following adjustment for confounding factors, the ORs of TC and TC+CC for asthma were 2.317 and 2.522 , respectively. There was a significant decrease in the forced expiratory volume $\left(\mathrm{FEV}_{1}\right)$ levels in patients with the TC genotype compared to the TT genotype of T1. Haplotype analysis revealed that the frequencies of Hap5 (CAC) and Hap6 (CAT) were significantly higher among asthmatic patients compared to healthy controls $(\mathrm{P}=0.024$
\end{abstract}

Correspondence to: Dr Qi-Man-Gu-Li Wu-Shou-Er, Department of Respiratory Medicine, The First Affiliated Hospital, Xinjiang Medical University, No. 1 Liyushan Road, Urumqi, Xinjiang 830054, P.R. China

E-mail: editsci@126.com

Key words: a disintegrin and metalloprotease domain 33, singlenucleotide polymorphisms, asthma, Uygur population, haplotype and 0.016, respectively). The genotype and allele frequencies of SNP S+1 and F+1 were not statistically different between asthmatic patients and controls. In conclusion, the ADAM33 T1 SNP may affect susceptibility to asthma in the Chinese Uygur population.

\section{Introduction}

Asthma is one of the most common types of chronic respiratory diseases, affecting $\sim 300$ million children and adults worldwide (1). It is well-known that asthma is affected by genetic as well as environmental factors and several genes have been shown to be associated with asthma $(2,3)$. A disintegrin and metalloprotease domain 33 (ADAM33) has been reported as a new member of the ADAM gene family (4). ADAM33 was the first putative asthma susceptibility gene to be identified by positional cloning in two Caucasian populations; one in the United Kingdom (UK) and the other in the United States of America (USA) (5). Since the first study on the association between ADAM33 polymorphisms and asthma, several replication studies have been published with conflicting results $(6,7)$.

However, these studies indicated a diversity in the relationship between ADAM33 polymorphisms and asthma. Possible reasons for such diversity may be the differences in the genetic background or environmental exposure that may affect the development of asthma. Thus, asthma susceptibility genes may differ among different nationalities. The majority of data currently available on ADAM33 and its correlation to asthma have been derived from Caucasian populations. Therefore, it is important to determine whether the findings in Caucasians may be replicated in different asthmatic populations. The Uygur population is located in the northwest of China and comprises $\sim 11,000,000$ people, with a relatively stable area of residence and little reported migration. The Uygur people are rarely associated with ethnic intermarriages and their lifestyles are consistent. Therefore, this is an ideal population for the conduction of genetic studies. The aim of the present study was to determine the association of ADAM33 single-nucleotide polymorphisms (SNPs) with asthma and asthma-related phenotypes in the Uygur population of China. 


\section{Subjects and methods}

Subjects. This study protocol was reviewed and approved by the Ethics Committee of Turpan Prefecture Hospital. Informed consent was obtained from all subjects. The study included 126 unrelated adults with a clinical diagnosis of asthma (mean age, 41.1 years; range, 16-79 years) and 126 healthy control subjects (mean age, 40.6 years; range, 18-78 years) from the Turpan Prefecture Hospital (Xinjiang, China). The healthy controls, who had no history of asthma, rhinitis, or other chronic pulmonary diseases, were matched 1:1 with patients by age ( \pm 5 years), gender, ethnic origin and area of residence. All the subjects were Chinese Uygur who resided in the area of Turpan, Xinjiang, China. All the subjects met the following criteria: i) no family history of diseases involving the candidate genes, such as immune system diseases; ii) no other severe diseases, such as severe infections, new-onset myocardial infarction, or stroke; and iii) long-term residence in the Xinjiang area (third generation or more).

Data collection and definition of risk factors. Information on demographic characteristics and other risk factors were collected using a structured questionnaire involving the following risk factors: history of allergy, family history of asthma, history of smoking, alcohol consumption, area of residence (urban or rural) and occupation. Family history of asthma was defined as first-degree relatives of the subjects diagnosed with asthma.

The serum-eosinophil cationic protein (S-ECP), total immunoglobulin $\mathrm{E}$ (T-IgE) and specific immunoglobulin $\mathrm{E}$ (S-IgE) levels were measured using the CAP system (Pharmacia Diagnostics, Uppsala, Sweden). The white blood cell counts were recorded and chest X-rays were performed.

DNA extraction and genotyping. Genomic DNA was extracted from $5 \mathrm{ml}$ of frozen whole blood using a DNA extraction kit (Qiagen, Hilden, Germany), according to the manufacturer's instructions. DNA samples were stored at $-80^{\circ} \mathrm{C}$. Based on the information in the NCBI SNP database (www. ncbi.nlm.nih. gov), we selected three SNPs in the ADAM33 gene, which had been previously shown to have an allelic and/or haplotypic association with asthma. The SNPs were T1 (rs2280091, $12433 \mathrm{~T} / \mathrm{C}$ in exon 20), S+1 (rs2853209, 11188A/T in intron 19) and $\mathrm{F}+1$ (rs511898, 7575G/A in intron 6). SNP details and sequence data are available in the NCBI databases through the unique accession numbers.

Genotyping by polymerase chain reaction-fragment length polymorphism (PCR-RFLP). Genotyping was performed by PCR-RFLP, as follows: all PCRs were conducted in a volume of $20 \mu \mathrm{l}$ containing $50 \mathrm{ng}$ of genomic DNA, $200 \mu \mathrm{m}$ of dNTP, $0.2 \mu \mathrm{m}$ of each primer, $1.5 \mathrm{mM} \mathrm{MgCl}_{2}$ and 1 unit of Taq DNA polymerase.

The T1 polymorphism was typed using sense (5'-AGAGGG TGACTTGGAGCAGA-3') and antisense (5'-CCAGAAACC TGATTAGGGGG-3') primers. Following PCR, the product was digested with 2 units $\mathrm{NcoI}$ (New England Biolabs, Hitchin, Hertfordshire, UK) for $4 \mathrm{~h}$ and the fragments were resolved on a $2 \%$ agarose gel. The PCR product was $576 \mathrm{bp}$ in length. Digestion of the PCR product yielded 576-bp bands in CC homozygotes, 383-bp and 193-bp bands in TT homozygotes and all three bands in heterozygotes. The $\mathrm{S}+1$ polymorphism was typed using sense (5'-CTTCCTCAGTGGCCTCCCAGT CAATCG-3') and antisense (5'-AGGGTGAGGCAGCCA GCT-3) primers. Following PCR, the product was digested with 2 units $T a q \mathrm{I}$ (New England Biolabs) for $4 \mathrm{~h}$ and the fragments were resolved on a 3.8\% agarose gel. The PCR product was $134 \mathrm{bp}$ in length. Digestion of the PCR product yielded 112-bp bands in AA homozygotes, 134-bp bands in TT homozygotes and both bands in heterozygotes. The $\mathrm{F}+1$ polymorphism was typed using sense (5'-GGGGAGCCCTCC AAATCAGAAGAGCC-3') and antisense (5'-AGTGGA AGCTGCTGGGCTT-3) primers. Following PCR, the product was digested with 2 units $M s p l$ (New England Biolabs) for $4 \mathrm{~h}$ and the fragments were resolved on a 3.8\% agarose gel. The PCR product was $154 \mathrm{bp}$ in length. Digestion of the PCR product yielded 125-bp bands in CC homozygotes, 154-bp bands in TT homozygotes and both bands in heterozygotes.

Statistical analysis. Differences in the allele and genotype frequencies were calculated using $\chi^{2}$ or Fisher's exact tests. The $\chi^{2}$ test was used to assess the deviation of the genotype distribution from the Hardy-Weinberg equilibrium (HWE). In addition, multivariate conditional regression analyses were performed to assess the independent role of the ADAM33 genotype and other risk factors. Odds ratios (ORs) with 95\% confidence intervals (95\% CIs) were calculated to evaluate the association between risk factors and asthma. Standard analysis of variance (ANOVA) was performed for quantitative trials. A 2-tailed $\mathrm{P}<0.05$ was considered to indicate a statistically significant difference. Haplotype analyses of the three ADAM33 SNPs were performed using PHASE 2.0 software (www.phase2medical.com).

\section{Results}

Subject characteristics. As shown in Table I, there were no significant differences in age or history of smoking between the two groups. Spirometric assessment revealed lower predicted percentage (\%) of forced expiratory volume $\left(\mathrm{FEV}_{1}\right)$ in asthma patients compared to healthy controls (77.52 \pm 12.78 vs. $98.21 \pm 7.45 \%, \mathrm{P}<0.001)$. The levels of $\mathrm{T}-\operatorname{IgE}$ and S-ECP were significantly higher in patients with asthma compared to those in healthy controls $(91.46 \pm 37.28$ vs. $43.52 \pm 28.44 \mathrm{kU} / 1$ and $6.67 \pm 1.45$ vs. $2.28 \pm 1.09 \mu \mathrm{g} / \mathrm{l}$, respectively $(\mathrm{P}<0.001)$. A higher percentage of asthmatic patients expressed S-IgE (30.95\%) compared to healthy controls (7.14\%). The prevalence of conventional risk factors for asthma was higher in the patient group and these risk factors included a family history of asthma and a history of allergy.

Distribution of ADAM33 polymorphisms. The asthmatic patients and healthy controls were in $\operatorname{HWE}\left(\chi^{2}=0.743 ; \mathrm{P}=0.416\right.$ and $\chi^{2}=1.765 ; \mathrm{P}=0.327$, respectively) for the $\mathrm{T} 1$ polymorphism. There was a significant association between the SNP T1 (Met764Thr) genotype and asthmatics (Table II). The frequency of the $\mathrm{C}$ allele was significantly increased in the asthma group compared to the healthy control group (20.6 vs. $11.1 \%$ ). The OR of the $\mathrm{C}$ allele to $\mathrm{T}$ allele was $2.080(\mathrm{P}=0.003)$. The frequencies of the TT, TC and CC genotypes in the two groups were $64.3 \%$ 
Table I. Demographic characteristics and distribution of risk factors.

\begin{tabular}{|c|c|c|c|}
\hline Characteristics & No. of patients (\%) & No. of controls $(\%)$ & P-value \\
\hline Subject no. & 126 & 126 & \\
\hline Age (years $\pm \mathrm{SD})$ & $41.06 \pm 9.75$ & $40.58 \pm 9.24$ & 0.401 \\
\hline \multicolumn{4}{|l|}{ Gender $(\%)$} \\
\hline Male & $66(52.38)$ & $66(52.38)$ & \\
\hline Female & $60(47.62)$ & $60(47.62)$ & \\
\hline \multicolumn{4}{|l|}{ Area of residence } \\
\hline Urban & $65(51.6)$ & $58(46.03)$ & 0.778 \\
\hline Rural & $61(48.4)$ & $68(53.97)$ & 0.778 \\
\hline History of smoking & $34(26.98)$ & $30(23.81)$ & 0.665 \\
\hline Family history of asthma & $29(23.02)$ & $5(3.97)$ & 0.000 \\
\hline History of allergy & $44(34.92)$ & $15(11.90)$ & 0.000 \\
\hline Positive S-IgE & $39(30.95)$ & $9(7.14)$ & 0.000 \\
\hline T-IgE (kU/l) & $91.46 \pm 37.28$ & $43.52 \pm 28.44$ & 0.000 \\
\hline $\mathrm{S}-\mathrm{ECP}(\mu \mathrm{g} / \mathrm{l})$ & $6.67 \pm 1.45$ & $2.28 \pm 1.09$ & 0.000 \\
\hline $\mathrm{FEV}_{1} \%$ predicted & $77.52 \pm 12.78$ & $98.21 \pm 7.45$ & 0.000 \\
\hline
\end{tabular}

SD, standard deviation; S-IgE, specific immunoglobulin E; T-IgE, total immunoglobulin E; S-ECP, serum-eosinophil cationic protein; $\mathrm{FEV}_{1}$, forced expiratory volume.

Table II. Genotype and allele distribution of ADAM33 polymorphisms.

\begin{tabular}{|c|c|c|c|c|c|c|c|c|c|c|}
\hline $\begin{array}{l}\text { Genotype } \\
\text { site }\end{array}$ & $\begin{array}{c}\text { No. of } \\
\text { patients }(\%)\end{array}$ & $\begin{array}{c}\text { No. of } \\
\text { control }(\%)\end{array}$ & $\chi^{2}$ & P-value & Allele & $\begin{array}{c}\text { No. of } \\
\text { patients }(\%)\end{array}$ & $\begin{array}{c}\text { No. of } \\
\text { patients }(\%)\end{array}$ & $\begin{array}{c}\text { OR } \\
(95 \% \mathrm{CI})\end{array}$ & $\chi^{2}$ & P-value \\
\hline \multicolumn{11}{|l|}{$\mathrm{T} 1$} \\
\hline $\mathrm{TT}$ & $81(64.3)$ & $101(80.2)$ & 8.064 & 0.018 & $\mathrm{~T}$ & $200(79.4)$ & $224(88.9)$ & $1.00^{\mathrm{a}}$ & & \\
\hline $\mathrm{TC}$ & $38(30.2)$ & $22(17.4)$ & & & $\mathrm{C}$ & $52(20.6)$ & $28(11.1)$ & 2.080 & 8.559 & 0.003 \\
\hline $\mathrm{CC}$ & $7(5.5)$ & $3(2.4)$ & & & & & & $(1.273-3.398)$ & & \\
\hline \multicolumn{11}{|l|}{$S+1$} \\
\hline AA & $36(28.6)$ & $33(26.2)$ & 1.020 & 0.601 & A & $133(52.8)$ & $123(48.8)$ & $1.00^{\mathrm{a}}$ & & \\
\hline AT & $61(48.4)$ & $57(45.2)$ & & & $\mathrm{T}$ & $119(47.2)$ & $129(51.2)$ & 0.853 & 0.794 & 0.373 \\
\hline $\mathrm{TT}$ & $29(23.0)$ & $36(28.6)$ & & & & & & $(0.601-1.210)$ & & \\
\hline \multicolumn{11}{|l|}{$\mathrm{F}+1$} \\
\hline $\mathrm{CC}$ & $67(53.2)$ & $70(55.6)$ & 0.172 & 0.917 & $\mathrm{C}$ & $185(73.4)$ & $189(75.0)$ & $1.00^{\mathrm{a}}$ & & \\
\hline $\mathrm{CT}$ & $51(40.5)$ & 49 (38.9) & & & $\mathrm{T}$ & $67(26.6)$ & $63(25.0)$ & 1.086 & 0.166 & 0.684 \\
\hline TT & $8(6.3)$ & $7(5.6)$ & & & & & & $(0.729-1.616)$ & & \\
\hline
\end{tabular}

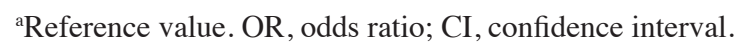

(81 cases), 30.2\% (38 cases) and 5.5\% (7 cases), respectively, among asthmatic patients and $80.2 \%$ (101 cases), $17.4 \%$ (22 cases) and $2.4 \%$ (3 cases), respectively, among healthy controls. There was a significant difference in the distribution of the TT, TC and $\mathrm{CC}$ genotypes between asthmatic and healthy subjects $\left(\chi^{2}=8.064 ; \mathrm{P}=0.018\right)$.

As regards the $\mathrm{S}+1$ and $\mathrm{F}+1$ polymorphisms, the asthmatic patients $\left(\chi^{2}=0.106\right.$ and 0.174 , respectively; $\left.P>0.05\right)$ and healthy controls $\left(\chi^{2}=1.149\right.$ and 0.176 , respectively; $\left.\mathrm{P}>0.05\right)$ were in HWE. There was no significant difference in the distributions of ADAM33 S+1 $(\mathrm{P}=0.601)$ and $\mathrm{F}+1(\mathrm{P}=0.917)$ between the asthmatic and healthy subjects.

Association of genotypes with the risk of asthma. The crude and adjusted ORs for asthma were used with and without adjustment for confounding factors. As shown in Table III, 
Table III. ORs of different ADAM33 genotypes for asthma.

\begin{tabular}{|c|c|c|c|c|c|c|}
\hline Genotype & Crude OR & $95 \% \mathrm{CI}$ & P-value & Adjusted OR & $95 \% \mathrm{CI}^{\mathrm{a}}$ & P-value \\
\hline \multicolumn{7}{|l|}{$\mathrm{T} 1$} \\
\hline TT & $1.00^{\mathrm{b}}$ & & & & & \\
\hline $\mathrm{TC}$ & 2.118 & $1.138-3.943$ & 0.016 & 2.317 & $1.102-4.870$ & 0.031 \\
\hline $\mathrm{CC}$ & 2.307 & $0.648-8.213$ & 0.192 & 2.678 & $0.589-12.184$ & NS \\
\hline $\mathrm{TC}+\mathrm{CC}$ & 2.244 & $1.279-3.938$ & 0.005 & 2.522 & $1.259-5.055$ & 0.014 \\
\hline \multicolumn{7}{|l|}{$\mathrm{S}+1$} \\
\hline AA & $1.00^{\mathrm{b}}$ & & & & & \\
\hline AT & 1.132 & $0.70-1.831$ & 0.621 & 1.119 & $0.672-1.665$ & NS \\
\hline $\mathrm{TT}$ & 0.781 & $0.482-1.263$ & 0.304 & 0.725 & $0.442-1.189$ & NS \\
\hline $\mathrm{AT}+\mathrm{AA}$ & 0.887 & $0.510-1.544$ & 0.672 & 0.794 & $0.434-1.453$ & NS \\
\hline \multicolumn{7}{|l|}{$\mathrm{F}+1$} \\
\hline $\mathrm{CC}$ & $1.00^{\mathrm{b}}$ & & & & & \\
\hline $\mathrm{CT}$ & 1.095 & $0.548-2.188$ & 0.813 & 1.147 & $0.386-3.046$ & NS \\
\hline TT & 1.187 & $0.336-4.185$ & 0.798 & 1.206 & $0.298-4.879$ & NS \\
\hline $\mathrm{CT}+\mathrm{TT}$ & 1.101 & $0.669-1.809$ & 0.704 & 1.123 & $0.608-2.076$ & NS \\
\hline
\end{tabular}

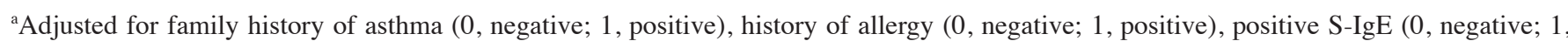
positive), total IgE, S-ECP and $\mathrm{FEV}_{1} \%$ predicted. ${ }^{\mathrm{b}}$ Reference group. OR, odds ratio; CI, confidence interval; NS, non-significant.

Table IV. Genotype distribution of ADAM33 polymorphisms among asthmatic patients.

\begin{tabular}{|c|c|c|c|c|}
\hline Genotype & No. of patients & $\mathrm{FEV}_{1} \%(\%)$ & T-IgE (kU/l) & $\mathrm{S}-\mathrm{ECP}(\mu \mathrm{g} / 1)$ \\
\hline \multicolumn{5}{|l|}{$\mathrm{T} 1$} \\
\hline TT & 81 & $80.74 \pm 12.85$ & $65.14 \pm 26.21$ & $5.38 \pm 1.32$ \\
\hline $\mathrm{TC}$ & 38 & $72.12 \pm 14.47$ & $72.86 \pm 28.25$ & $6.16 \pm 1.40$ \\
\hline $\mathrm{CC}$ & 7 & $74.96 \pm 12.08$ & $66.23 \pm 26.18$ & $5.29 \pm 1.25$ \\
\hline F-value & & 5.546 & 1.079 & 1.505 \\
\hline P-value & & 0.005 & 0.344 & 0.226 \\
\hline \multicolumn{5}{|l|}{$\mathrm{S}+1$} \\
\hline AA & 36 & $78.29 \pm 13.61$ & $67.05 \pm 26.58$ & $5.74 \pm 1.38$ \\
\hline AT & 61 & $75.32 \pm 12.94$ & $68.64 \pm 27.40$ & $5.65 \pm 1.34$ \\
\hline TT & 29 & $76.28 \pm 13.44$ & $65.78 \pm 25.91$ & $5.36 \pm 1.29$ \\
\hline F-value & & 0.570 & 0.120 & 0.229 \\
\hline P-value & & 0.567 & 0.887 & 0.795 \\
\hline \multicolumn{5}{|l|}{$\mathrm{F}+1$} \\
\hline $\mathrm{CC}$ & 67 & $76.06 \pm 13.04$ & $67.26 \pm 26.67$ & $5.52 \pm 1.31$ \\
\hline $\mathrm{CT}$ & 51 & $76.31 \pm 13.58$ & $68.35 \pm 27.29$ & $5.78 \pm 1.41$ \\
\hline TT & 8 & $77.15 \pm 12.87$ & $64.21 \pm 25.16$ & $5.28 \pm 1.15$ \\
\hline F-value & & 0.030 & 0.088 & 0.264 \\
\hline P-value & & 0.971 & 0.916 & 0.769 \\
\hline
\end{tabular}

$\mathrm{FEV}_{1}$, forced expiratory volume; T-IgE, total immunoglobulin E; S-ECP, serum-eosinophil cationic protein.

following adjustment for family history of asthma $(0$, negative; 1 , positive), history of allergy ( 0 , negative; 1 positive) and positive $\mathrm{S}-\mathrm{IgE}(0$, negative; 1 positive) by multiple logistic regression analysis, there was no significantly increased risk associated with the $\mathrm{S}+1$ and $\mathrm{F}+1$ genotypes or combinations of genotypes $(\mathrm{P}>0.05)$. Without adjustment for other confounding factors, the ADAM33 T1 TC genotype had an OR of 2.118 $(\mathrm{P}=0.016)$ compared to the TT genotype. Following adjustment for the above-mentioned confounding factors, the OR of the TC to the TT genotype was 2.317 . The T1 genotype 
Table V. Frequencies of three SNP haplotypes and odds ratios in asthma.

\begin{tabular}{|c|c|c|c|c|c|c|c|c|}
\hline \multirow[b]{2}{*}{ Haplotype } & \multicolumn{3}{|c|}{ SNP position } & \multicolumn{2}{|c|}{ Haplotype frequency } & \multirow[b]{2}{*}{$\chi^{2}$} & \multirow[b]{2}{*}{ P-value } & \multirow[b]{2}{*}{ OR $(95 \% \mathrm{CI})$} \\
\hline & $\mathrm{T} 1$ & $\mathrm{~S}+1$ & $\mathrm{~F}+1$ & Patient no. $(\%)$ & Control no. (\%) & & & \\
\hline 1 & $\mathrm{~T}$ & A & $\mathrm{C}$ & $68(27.0)$ & $92(36.5)$ & 5.274 & 0.022 & $0.643(0.441-0.937)$ \\
\hline 2 & $\mathrm{~T}$ & A & $\mathrm{T}$ & $15(6.0)$ & $8(3.2)$ & 2.232 & 0.135 & $1.930(0.814-4.573)$ \\
\hline 3 & $\mathrm{~T}$ & $\mathrm{~T}$ & $\mathrm{C}$ & $88(34.9)$ & $80(31.7)$ & 0.571 & 0.450 & $1.154(0.796-1.673)$ \\
\hline 4 & $\mathrm{~T}$ & $\mathrm{~T}$ & $\mathrm{~T}$ & $29(11.5)$ & $44(17.5)$ & 3.604 & 0.058 & $0.615(0.372-1.016)$ \\
\hline 5 & $\mathrm{C}$ & A & $\mathrm{C}$ & $28(11.1)$ & $14(5.6)$ & 5.091 & 0.024 & $2.125(1.110-4.417)$ \\
\hline 6 & $\mathrm{C}$ & A & $\mathrm{T}$ & $22(8.7)$ & $9(3.6)$ & 5.809 & 0.016 & $2.583(1.194-5.587)$ \\
\hline
\end{tabular}

$\chi^{2}=20.310, P=0.002$, asthmatics vs. controls. OR, odds ratio; CI, confidence interval; SNP, single-nucleotide polymorphism.

( $\mathrm{TC}+\mathrm{CC})$ was associated with an increased risk of asthma $(\mathrm{OR}=2.244 ; \mathrm{P}=0.005)$ compared to the TT genotype, without adjustment for confounding factors. Following adjustment for confounding factors, the OR for asthma was 2.522 for subjects with the ADAM33 variant genotype $(\mathrm{P}=0.014)$.

Association of the ADAM33 phenotypes with $F E V_{1} \%$ and $T$-IgE and S-ECP levels. As regards the T1 polymorphism, there were significant differences in $\mathrm{FEV}_{1} \%$ levels among TT, TC and $\mathrm{CC}$ genotypes $(\mathrm{F}=5.546, \mathrm{P}=0.005)$ (Table IV). Lower levels of $\mathrm{FEV}_{1}$ were observed in the TC genotype $\left(\mathrm{FEV}_{1} \%\right.$, $72.12 \pm 14.47 \%)$ compared to the TT genotype $\left(\mathrm{FEV}_{1} \%\right.$, $80.74 \pm 12.85 \%)$ of $\mathrm{T} 1(\mathrm{q}=4.384, \mathrm{P}<0.01)$. As regards the $\mathrm{S}+1$ and $\mathrm{F}+1$ gene polymorphisms, there was no significant difference in $\mathrm{FEV}_{1} \%$, T-IgE and S-ECP levels among the different genotypes $(\mathrm{P}>0.05)$.

Haplotype frequencies of the ADAM33 gene. The haplotype structure was analyzed using three SNPs $(\mathrm{T} 1, \mathrm{~S}+1$ and $\mathrm{F}+1)$ and six common haplotypes were identified in the two groups (Table V). There was a significant difference in the distribution of haplotypes between asthmatic patients and healthy controls $\left(\chi^{2}=20.310, P=0.002\right)$. The frequencies of Hap5 (CAC) and Hap6 (CAT) were significantly higher among asthmatic patients compared to healthy controls $(\mathrm{P}=0.024$ and $0.016, \mathrm{OR}=2.125$ and 2.538 , respectively). The frequency of Hap1 (TAC) was significantly lower in asthmatic compared to healthy subjects $(\mathrm{P}=0.022, \mathrm{OR}=0.643)$.

\section{Discussion}

The ADAM gene family, of which there currently are 34 members, is a subgroup of the zinc-dependent metalloproteinase superfamily $(8,9)$. Previous studies have demonstrated that ADAM family members are involved in fundamental processes, such as cell adhesion, fusion, migration, membrane protein shedding and proteolysis $(8,10)$. ADAM33, which was recently identified as a novel asthma susceptibility gene, maps to human chromosome 20p13, consists of 22 exons and a total of 37 SNPs have been identified (5). Various associations of ADAM33 SNPs with asthma, chronic obstructive pulmonary disease (COPD) and bronchial hyperresponsiveness (BHR) have been reported by previous studies (11-13). ADAM33 is a complex molecule, the expression of which is largely restricted to mesenchymal cells, including smooth muscle cells of the bronchi and pulmonary fibroblasts; thus, it is important in airway remodeling $(14,15)$.

The three SNPs used in this study have been previously reported to be associated with asthma and BHR in Caucasian populations in the UK or the USA; however, the association was not significant in the two samples combined (5). Associations with asthma were then replicated in US Caucasians (T1 and T2), in a German family-based study sample (F+1) (16) and in pediatric and adult Japanese populations (17). However, no SNP has been consistently associated with asthma across ethnically diverse groups. Therefore, different SNPs of the ADAM33 gene may contribute to asthma susceptibility in specific ethnic populations.

SNP T1 (Met764Thr) in exon 20 encodes the cytoplasmic domain. The substitution of thymine for cytosine in the T1 SNP results in the substitution of methionine for threonine in the cytoplasmic domain of the protein and this may alter intracellular signaling, resulting in increased fibroblast and smooth muscle cell proliferation.

The rare allele of T1 (T1 C) exhibited increased frequency among asthmatic patients compared to healthy controls in the previously studied Caucasian (24.1 vs. 7.4\%) (5), Japanese (15.3 vs. $5.3 \%$ ) and Korean populations (9 vs. 8\%) (17,18). Our study also demonstrated similar results (20.6 vs. 11.1\%). There were significant differences in the allele frequency distribution of the T1 locus between asthmatic patients and healthy controls $\left(\chi^{2}=8.559, \mathrm{P}=0.003\right)$. Compared to the $\mathrm{C}$ allele, the $\mathrm{T}$ allele demonstrated a 2.08-fold increased risk of asthma $(\mathrm{OR}=2.08$; 95\% CI, 1.273-3.398). Our results revealed that the ADAM33 T1 TC genotype had an OR of $2.118(\mathrm{P}=0.016)$ compared to the ADAM33 T1 CC genotype, without adjustment for other confounding factors. Multiple logistic regression analysis demonstrated that the T1 TC genotype is an independent genetic factor for asthma $(\mathrm{OR}=2.317, \mathrm{P}=0.031)$ compared to the TT genotype, following adjustment for other confounding factors. Similarly, significant associations with asthma were demonstrated for T1 (Met764Thr), T2 (Pro774Ser), S2 and $\mathrm{V}-3$ (with the lowest $\mathrm{P}$-value for $\mathrm{T} 1, \mathrm{P}=0.0015$; OR 0.63) in the Japanese population (17). Differences in the frequency of SNPs in asthmatic patients and healthy controls as reported by different studies have been summarized by Postma and 
Howard (19). We demonstrated significant associations with asthma in SNPs (T1). Our results were consistent with those of a study conducted by Schedel et al on a German population (20).

Foley et al (21) demonstrated an increase in the expression of the ADAM33 gene associated with the increase in the severity of asthma. This gene may contribute to the remodeling process that occurs during the progression of asthma. In addition, recent studies demonstrated that SNPs in ADAM33 are associated with an accelerated decline in pulmonary function in the general population and were identified as a risk factor for COPD $(11,22)$. The present study demonstrated a significant difference in $\mathrm{FEV}_{1}$ levels among different $\mathrm{T} 1$ genotypes. Lower $\mathrm{FEV}_{1}$ levels were observed in the TC compared to the TT genotype, a finding consistent with those of Simpson et al (23), who verified that ADAM33 polymorphisms affect pulmonary function during childhood and early life and may increase the risk of asthma. In the present study, there were no differences in the levels of total serum $\operatorname{IgE}$ and ECP among the $\mathrm{T} 1, \mathrm{~S}+1$ and $\mathrm{F}+1$ genotypes. We also observed no association between ADAM33 and allergy. In agreement with the findings of Umland et al (24), this study has demonstrated that ADAM33 mRNA is significantly expressed in smooth muscle-containing organs and minimally expressed in immune organs, suggesting a role for ADAM33 in remodeling, rather than in the immune response.

Two of the SNPs we investigated have been previously reported to be associated with asthma and BHR in Caucasian populations from the UK (intron $6,7575 / \mathrm{F}+1$ ) and the USA (exon 20, 12433/T1) (5). Werner et al (16) demonstrated that SNP F+1 of the ADAM33 gene is associated with asthma with the lowest P-value in that study. Simpson et al (23) demonstrated that carriers of the rare allele, $\mathrm{F}+1$, exhibited reduced pulmonary function at 3 years of age $(\mathrm{P}=0.003)$. When the recessive model was considered, four SNPs (F1, S1, ST5 and V-4) had an association with specific airway resistance (sRaw) at 5 years of age $(\mathrm{P}<0.04)$. Polymorphisms in ADAM33 predict impaired pulmonary function in early life. The functionally relevant polymorphism is likely to be located at the 5 ' end of the gene. A meta-analysis demonstrated that only 2 out of the 13 studied variants $(\mathrm{F}+1$ and $\mathrm{ST}+7$, in strong linkage disequilibrium), were significantly associated with asthma in the unrelated case-control data and the family-based data (25). Significant associations of asthma with the S+1, ST+4 and T2 sites and with the T1, $\mathrm{T} 2, \mathrm{~S} 2$ and V-3 sites have been reported in pediatric and adult Japanese populations, respectively (17). Raby et al (26) reported 8 additional SNPs (S+1, G1, I1, KL+3, N1, T+2, V-2 and V-3). None of the additional SNPs had an association with asthma.

In the present study, we determined the association between the $\mathrm{S}+1$ and $\mathrm{F}+1$ polymorphisms and asthma in the Chinese Uygur population. The study did not demonstrate a difference in the alleles and genotypes between the two groups. Our results indicated that the $\mathrm{S}+1$ and $\mathrm{F}+1$ polymorphisms in the ADAM33 gene are not associated with susceptibility to asthma. Part of the results of our study are in agreement with the results of Schedel et al (20), while the findings suggest that the $\mathrm{F}+1$ polymorphism of the ADAM33 gene is not associated with asthma.
It has been demonstrated that the ADAM33 gene is involved in the pathogenesis of asthma (27). The T1 polymorphic site of the ADAM33 gene is associated with susceptibility to asthma in the Uygur ethnic group. The $\mathrm{T}$ allele may be protective, whereas the $\mathrm{C}$ allele may increase susceptibility to asthma. The potential mechanism underlying the association of the T1 locus SNP to asthma may be that the T1 locus SNP leads to decreased $\mathrm{FEV}_{1}$ levels and increased susceptibility to asthma. However, in a study of 290 patients and 270 controls in a Chinese Han population, Wang et al (28) did not identify a significant association of the $\mathrm{F}+1, \mathrm{~S}+1$ and $\mathrm{T} 1 \mathrm{SNPs}$ with bronchial asthma. The Uygur population is a mixture of European (40-60\%) and East Asian ancestry and is thus different from other Chinese populations. Several findings are not reproducible, due to a number of confounding variables (e.g., age, gender and ethnic background). If we determine the association of specific polymorphisms of a specific gene with asthma, the benefits of studying the association between gene polymorphisms and diseases are probably limited. In addition, the diversity of the results regarding common polymorphisms of the ADAM33 gene, such as $\mathrm{F}+1$ or $\mathrm{S}+1$, are possibly related to gene-gene and gene-environment interactions. Undarmaa et al (29) reported that interactions between TBXA2R and ADAM33 may increase the risk of childhood asthma and adult/childhood asthma combined. Stratification of the subjects by environmental or other confounding factors may be required to improve the sensitivity and reliability of the association results.

In a multi-locus haplotype analysis, the ADAM33 gene haplotype profile is significantly different between patients and controls in the Uygur ethnic group. The frequencies of the CAC and CAT haplotypes are higher among asthmatic patients compared to healthy controls, suggesting that these two haplotypes increase the risk of asthma. Furthermore, we observed that the frequency of the TAC haplotype was lower among asthmatic patients compared to healthy controls. This result suggests that there are ethnic-specific disease-predisposing or -protecting haplotypes of asthma in the Chinese Uygur population.

In conclusion, this study demonstrated the association between ADAM33 gene polymorphisms and the risk of asthma in the Chinese Uygur population. To confirm the significance of these observed polymorphisms, definitions and standardization of phenotypes, endorsement from several investigators is required. Large-scale testing platforms may offer new opportunities for discovering susceptibility gene variants; however, they should be coupled with careful study design, international collaboration and dissection of gene-environment interactions.

\section{Acknowledgements}

The authors would like to express their gratitude to Mr. Tao Liu, Ms. Jun-hua Wang and Dr Li-ping Zhang for their clinical and technical assistance, to Dr. H. Schmidt of the Institute of Molecular Biology and Biochemistry, Medical University of Graz, Austria, for the review of the manuscript, to Mr. Qi Sun for his help with statistical analysis and to the subjects and their families for their participation in this study. The present study was supported by grant no. 81100026 from the National Natural Science Foundation of China. 


\section{References}

1. Lima JJ, Mohapatra S, Feng H, Lockey R, et al: A polymorphism in the NPPA gene associates with asthma. Clin Exp Allergy 38 $1117-1123,2008$

2. Zhang Y, Zhang J, Huang J, Li X, et al: Polymorphisms in the transforming growth factor-betal gene and the risk of asthma: a meta-analysis. Respirology 15: 643-650, 2010.

3. Denham S, Koppelman GH, Blakey J, Wjst M, et al: Meta-analysis of genome-wide linkage studies of asthma and related traits. Respir Res 9: 38, 2008

4. Yoshinaka T, Nishii K, Yamada K, et al: Identification and characterization of novel mouse and human ADAM33s with potential metalloprotease activity. Gene 282: 227-236, 2002.

5. Van Eerdewegh P, Little RD, Dupuis J, Del Mastro RG, et al: Association of the ADAM33 gene with asthma and bronchial hyperresponsiveness. Nature 418: 426-430, 2002.

6. Haward TD, Postma DS, Jongepier H, et al: Association of a disinterin and metalloproteinase 33 (ADAM33) gene with asthma in ethnical diverse populations. J Allergy Clin Immunol 112: 717-722, 2003.

7. Lind DL, Choudhry S, Ung N, et al: ADAM33 is not associated with asthma in Puerto Rican or Mexican populations. Am J Respir Crit Care Med 168: 1312-1316, 2003.

8. Primakoff P and Myles DG: The ADAM gene family: surface proteins with adhesion and protease activity. Trends Genet 16: $83-87,2000$

9. Stone AL, Kroeger M and Sang QX: Structure-function analysis of the ADAM family of disintegrin-like and metalloproteinase containing proteins. J Protein Chem 18: 447-465, 1999.

10. Black RA and White JM: ADAMs: focus on the protease domain. Curr Opin Cell Biol 10: 654-659, 1998

11. Sadeghnejad A, Ohar JA, Zheng SL, et al: Adam33 polymorphisms are associated with COPD and lung function in long-term tobacco smokers. Respir Res 10: 21, 2009.

12. ten Brinke A: Risk factors associated with irreversible airflow limitation in asthma. Curr Opin Allergy Clin Immunol 8: 63-69, 2008.

13. Vergara CI, Acevedo N, Jiménez S, Martínez B, et al: A six-SNP haplotype of ADAM33 is associated with asthma in a population of Cartagena, Colombia. Int Arch Allergy Immunol 152: 32-40, 2010.

14. Holgate ST: ADAM metallopeptidase domain 33 (ADAM33): identification and role in airways disease. Drug News Perspect 23: 381-387, 2010.

15. Puxeddu I, Pang YY, Harvey A, Haitchi HM, et al: The soluble form of a disintegrin and metalloprotease 33 promotes angiogenesis: implications for airway remodeling in asthma. J Allergy Clin Immunol 121: 1400-1406, 2008.
16. Werner M, Herbon N, Gohlke H, et al: Asthma is associated with single-nucleotide polymorphisms in ADAM33. Clin Exp Allergy 34: 26-31, 2004.

17. Noguchi E, Ohtsuki Y, Tokunaga K, et al: ADAM33 polymorphisms are associated with asthma susceptibility in a Japanese population. Clin Exp Allergy 36: 602-608, 2006.

18. Lee JH, Park HS, Park SW, et al: ADAM33 polymorphism: association with bronchial hyper-responsiveness in Korean asthmatics. Clin Exp Allergy 34: 860-865, 2004.

19. Postma DS and Howard T: ADAM33 gene: confirming a gene without linkage. Clin Exp Allergy 34: 1-3, 2004.

20. Schedel M, Depner M, Schoen C, Weiland SK, et al: The role of polymorphisms in ADAM33, a disintegrin and metalloprotease 33 , in childhood asthma and lung function in two German populations. Respir Res 7: 91, 2006.

21. Foley SC, Mogas AK, Olivenstein R, et al: Increased expression of ADAM33 and ADAM8 with disease progression in asthma. J Allergy Clin Immunol 119: 863-871, 2007.

22. van Diemen CC, Postma DS, Vonk JM, Bruinenberg M, Schouten JP, et al: A disintegrin and metalloprotease 33 polymorphisms and lung function decline in the general population. Am J Respir Crit Care Med 172: 329-333, 2005.

23. Simpson A, Maniatis N, Jury F, Cakebread JA, et al: Polymorphisms in a disintegrin and metalloprotease 33 (ADAM33) predict impaired early life lung function. Am J Respir Crit Care Med 172: 55-60, 2005.

24. Umland SP, Garlisi CG, Shah H, et al: Human ADAM33 messenger RNA expression profile and post-transcriptional regulation. Am J Respir Cell Mol Biol 29: 571-582, 2003.

25. Blakey J, Halapi E, Bjornsdottir US, Wheatley A, et al: Contribution of ADAM33 polymorphisms to the population risk of asthma. Thorax 60: 274-276, 2005.

26. Raby BA, Silverman EK, Kwiatkowski DJ, et al: ADAM33 polymorphisms and phenotype associations in childhood asthma. J Allergy Clin Immunol 113: 1071-1078, 2004.

27. Cakebread JA, Haitchi HM, Holloway JW, et al: The role of ADAM33 in the pathogenesis of asthma. Springer Semin Immunopathol 25: 361-375, 2004.

28. Wang P, Liu QJ, Li JS, et al: Lack of association between ADAM33 gene and asthma in a Chinese Population. Int J Immunogenet 33: 303-306, 2006.

29. Undarmaa S, Mashimo Y, Hattori S, et al: Replication of genetic association studies in asthma and related phenotypes. J Hum Genet 55: 342-349, 2010. 